\title{
Scaffolding Strategy and Customized Instruction Efficiency in Teaching English as a Foreign Language in the Context of Saudi Arabia
}

\author{
Dr. Elsadig Ali Elsadig Elandeef $\quad$ Dr. Ayman Hamad Elneil Hamdan \\ King Khalid University - College of Sciences \& Arts- Dhahran Aljanoub, KSA.
}

The authors extend their appreciation to the Deanship of Scientific Research at King Khalid University for funding this work through General Research Project under grant number (project number: 76 /year: 2021)

\section{Abstract}

This study investigates how to teach English in optimal way using scaffolding, consideration of the learners' needs and preference in the context of Saudi Arabia. The study entails the role of scaffolding strategy, personification, differentiation, individualization and customization in maximizing teaching English's quality and facilitation of learning process. The study is based on descriptive approach and the researchers use a questionnaire as an instrument of data collection. The findings of the study have revealed that using scaffolding and implementing customized instructions in teaching English in Saudi Arabia context maximizes teaching's quality, grasp learners' awareness and interactivity. The study recommends that customized instruction and customized syllabus should be implemented in English class in Saudi Arabia,

Keywords: customization, differentiation, personification, individualization, scaffolding, efficiency

DOI: $10.7176 /$ JLLL/77-05

Publication date:March $31^{\text {st }} 2021$

\subsection{Introduction}

Learning English requires satisfaction of learners' needs and preferences through instruction and syllabus. Thus, the focal core of teaching and learning process is the learner and customized teaching plays a crucial role to satisfy the learners' needs and preferences. Customization is firmly linked to the way in which the needs of learners are met, so each learner finds nearly exactly what they want. Customized instruction satisfies the demands for learners' satisfaction. Customized learning seeks to gear classroom content, instruction, and other aspects of learning towards individual students, their unique interests, and past learning experiences (Hattie, 2009). Customized learning involves differentiation, individualization and personification strategies. These strategies cover variations in the organization of education at the school level as well as in the pedagogical handling of the learning content at the classroom level (Levy, 2008).Tomlinson (1999) suggests that every teacher can meet the manifest diversity in educational demands of pupils by means of differentiated instruction, which is a set of strategies that will help teachers meet each child where they are when they enter class and move them forward as far as possible on their educational path. Individualization refers to the set of didactic strategies aiming to guarantee all students' mastery of the same learning objectives by adjusting the pace to the progression of the learner. Personalized learning refers to the learning that is tailored to the preferences and interests of various learners, as well as instruction that is paced to a student's unique needs (Gee,2007). 'Scaffolding as a teaching strategy originates from Lev Vygotsky's sociocultural theory and his concept of the zone of proximal development (ZPD). In scaffolding strategy provides scaffolds or supports to facilitate the learner's development. The scaffolds facilitate a student's ability to build on prior knowledge and internalize new information. The activities provided in scaffolding instruction are just beyond the level of what the learner can do alone (Olson \& Pratt, 2000). An important aspect of scaffolding strategy is that the scaffolds are temporary. As the learner's abilities increase the scaffolding provided by the more knowledgeable other is progressively withdrawn. Finally the learner is able to complete the task or master the concepts independently (Chang, Sung, \& Chen, 2002). Therefore the goal of the educator when using the scaffolding teaching strategy is for the student to become an independent and self-regulating learner and problem solver (Hartman, 2002). As the learner's knowledge and learning competency increases, the educator gradually reduces the supports provided (Raymond, 2000)

1-Scaffolding is a temporal strategy for supporting and facilitating the learner's development. The scaffolds facilitate a student's ability to build on prior knowledge and internalize new information. The activities provided in scaffolding instruction are just beyond the level of what the learner can do alone (Olson \& Pratt, 2000). The more capable other provides the scaffolds so that the learner can accomplish with assistance the tasks that he or she could otherwise not complete, thus helping the learner through the ZPD (Bransford, Brown, \& Cocking, 2000).

The study aims at investigating the efficiency of implementation customized instruction and scaffolding strategy in teaching English in the context of Saudi Arabia. 


\subsection{Statement of the Problem}

Many English teachers do not use customized instruction and scaffolding strategy in teaching English in Saudi Arabia context. Most of them rely on teacher centered approach and regard teacher as source of knowledge. The challenge for these involves that teaching does not consider the needs and preference of the learners. As the result, English language teachers face difficulties while teaching English in the context of Saudi Arabia because they tackle reluctant, demotivated and exam-oriented students.

\subsection{Aims of the Study}

This study aims to:

1. Identify the challenges facing English teachers when teaching English without implementation of customized instruction and scaffolding strategy.

2. Raise teachers' awareness of using customized instruction and scaffolding strategy.

3. Shed light the implementation of customized instruction and scaffolding strategy in the context of Saudi Arabia.

\subsection{Questions of the Study}

1. What type of professional training do English teachers have in implementing customized instruction and scaffolding strategies?

2. How do customized instruction and scaffolding strategies facilitate teaching and accelerate learning English?

3. What problems do teachers face when they do not implement customized instruction and scaffolding strategies?

\subsection{Hypotheses of the Study}

1-There is a lack of pedagogical in-service training in implementing customized instruction and scaffolding strategies.

2-Customized instruction and scaffolding strategies facilitate teaching and learning through considering the needs and preferences of Saudi learners

3-Teachers face several types of difficulties when they do not implement customized instruction and scaffolding strategies.

\subsection{Significance of the Study}

The findings will hopefully help school English teachers to seek to understand the benefits of customized instruction and scaffolding strategies in facilitating and accelerating teaching and learning process in the context of Saudi Arabia. Furthermore, teachers, syllabus designers, and policy makers will find relevant points to their pedagogical decisions.

1.6 Research Methodology

The instrument of data collection for the research was a questionnaire consisting of a twenty-five statement and the researcher's overt observation. The subjects were chosen purposively from Aseer Schools' English language teachers. The researcher conducted a pilot survey and used statistical techniques through which validity and reliability of the questionnaire were verified. The overall research method used was the descriptive method.

\subsection{Delimitation of the Study}

The study was conducted in Asir Schools- Abha, Dhran Aljanoub, Dhran Aljanoub, Khamis Mashit, Sarat Abeida and Hud Rufida, KSA. Aseer Schools include intermediate, and secondary schools. The research was conducted in the school year(2020).

\subsection{Review of Literature}

\subsection{Customized Instruction}

Students learn at different speeds, different preferences and in different ways. Thus, customized instruction allows the teacher to adapt their lessons to a variety of learning styles and needs, giving their students the best possible chance for growth. Even though a customized approach to instruction may take time, adjustments to instruction and preparation, it can make a big difference over time (McTighe and Brown 2005). Tseng and Jiao (2001) defined customization as the technologies and systems to deliver goods and services that meet individual customers' needs with near mass production efficiency. For education, this is not equivalent to personalized learning. The process of ${ }^{2}$ customization in educational terms is based on a demand from a group of learners where the combination of learning materials, learning services, and teaching efforts should fulfill certain explicit or implicit requirements and a supply of building blocks that can be combined into an offer fulfilling the demand. In 
Wikipedia1, personalized learning is defined as "the tailoring of pedagogy, curriculum and learning environments to meet the needs and aspirations of individual learners."

According to the U.S. Department of Education (2010, p. 12), personalization is considered as encompassing individualization and differentiation: Individualization refers to instruction that is paced to the learning needs of different learners. Learning goals are the same for all students, but students can progress through the material at different speeds according to their learning needs. For example, students might take longer to progress through a given topic, skip topics that cover information they already know, or repeat topics they need more help on.

$\overline{2-C u s t o m i z a t i o n ~ i n s t r u c t i o n ~ r e f e r s ~ t o ~ e d u c a t o r s ~ u s i n g ~ s p e c i f i c ~ s t r a t e g i e s, ~ r e s o u r c e s ~ a n d ~ a s s e s s m e n t s ~ t h a t ~ c a t e r ~ t o ~}$ the needs, preferences, pace and learning style of learners in their class. This process ensures that students are given guidance and flexibility in their learning process. Furthermore, Customized instruction is defined as the tailoring of pedagogy, curriculum and learning environments to meet the needs and aspirations of individual learners. It involves personification entailing individualization and differentiation. The process of customization in terms of educational is based on a demand from a group of learners where the combination of learning materials, learning services, and teaching efforts should fulfill certain explicit or implicit requirements and a supply of building blocks of learning materials, services, and teaching efforts that can be combined into an offer fulfilling the demand.

Whereas, differentiation refers to instruction tailored to the learning preferences of different learners. Personalization refers to instruction that is paced to learning needs, tailored to learning preferences, and tailored to the specific interests of different learners. In an environment that is fully personalized, the learning objectives and content as well as the method and pace may all vary. Thus, personalization encompasses differentiation and individualization. Customization involves personification, differentiation and individualization (Salser, 2001).

Tseng and Jiao(2001) stated that customization means that learners are able to adjust the learning process to accommodate their own interests, needs, learning style, and objectives and it is known as adaptive learning. Furthermore, customization is based on two main concepts: first, that everyone learns at a different pace and second, that everyone learns in different ways. Tomlinson (2001) contended that customized learning means presenting materials and skill development opportunities to students in a modality that is tailored specifically for each individual student. In addition, it is a project based learning, where learners get involved in what intrinsically interests them, create projects that demonstrate knowledge and skill acquisition, and fully embrace the goal of becoming lifelong learners. The broad goal of these efforts is to achieve the democratization of education. Burton (2003). observed that classrooms adopting this principle would allow students to discover their favored learning styles and to try new ones without fear. In the act of customizing their own learning, students would learn a good deal about their own thinking, reflection, and ways of solving problems. Bates (2005) noted that student diversity within the technological era has to be considered also:Learners are not a homogenous mass, but vary considerably in terms of educational background, income, age and learning experience. This diversity of the student body is growing fast. It will become increasingly important for educational organizations to be able to deliver their teaching in a variety of technological formats, depending on the needs of the individual, the teaching context, and the target groups to be reached. A customized instruction utilizes personalized learning strategies to meet the needs of individual students is particularly beneficial because it seeks to address the personal needs of individual students (Mistree, Panchal and Dirk (2012). Customized instruction can provide: Students set the pace of learning within a classroom and customized curriculum allows teachers to personalize their lesson plans to meet the needs of individual students, allowing these students to move at the pace that will best help them reach their potential; ${ }^{1}$ Maintaining student engagement due to the tailoring the lessons to meet the needs of students and allowing them to learn at a pace that is natural for them, helps to ensure that students stay engaged in the material; Having the flexibility of customizable curriculums also means that teachers can help gifted students to move through their lessons more quickly. This means that students who display a particular talent in a subject have the opportunity to proceed to more difficult work. For example, students who show a particular passion for science can proceed through the curriculum more quickly and even have a chance to participate in science projects and research. With this teaching style, the sky is truly the limit for our students; A one-on-one time with teachers greatly helps in the creation of this safe space. When students have one-on-one time with their educators, they are more likely to open up and share any struggles that they may encounter in class more freely. They might talk about a particular difficulty in a subject, or complain about mistreatment from a fellow classmate. With opportunities of one-on-one time with their teachers being available,

1- Classroom engagement is a key predictability of student success; the more students pay attention, the more they're likely to absorb..The classroom also functions as a more coherent unit when the teacher commands the respect and the engagement of all the students. Students who are faster learners can contribute to helping their peers who need more time; their peers who need more help can ask questions freely and get the answers that they need.

students are given the individual attention they need to ensure they reach their potential and are presented with 
unique, personalized learning opportunities they would not receive in most classrooms; Customized instruction also tends to emphasize having smaller student-to-teacher ratios. This means that there are fewer students in a classroom, and gives room for the teacher to interact with and understand the needs of each one. Smaller class sizes also do wonders to help ensure that your child gets the individual attention that he or she needs. For example, in art class, the teacher has the time to actually go around to each student to examine their progress and offer helpful tips. Each student can proceed at their own pace, confident of getting the attention that they need (Tseng and Jiao, 2001).

\subsubsection{Reasons Why Customized Instruction is Necessary}

McTighe and Brown, J. (2005) mentioned four reasons why customized instruction is necessary:

-Students are able to learn at their pace: Customized instruction is designed to give students multiple ways to approach a single new concept and students are able to follow the method that makes the most sense to them and best suits their strengths. As a result, they learn the material more quickly and are able to apply it and expand upon it. Not only does this help them gain more confidence in the subject matter, but it keeps them learning at a pace that makes sense for them.

-Teachers will find more overall flexibility: Customized instruction allows for a more flexible, dynamic classroom. Simple adjustments to the lesson (for example, allowing students a choice of a visual, auditory, or hands-on method of approaching the topic and it can provide a fun new way to approach lesson planning.

-Students can comfortably learn new skills: While a student may lean on their primary method of learning at first, the confidence their successes give them will eventually allow them to try new things. Certain types of activities, such as menu boards and flexible grouping, may be designed to challenge students to step outside of their comfort zone. In doing this, it provides a safe atmosphere for students to improve upon their weaker areas while still falling back on what they are most confident in.

- Teachers and students alike will see more results: When students enjoy learning, and the learning feels tailored to their individual needs, it becomes more enjoyable. As a result, they are more likely to achieve at a higher level and remember the content over time. It also becomes easier for teachers to identify when students are struggling with a concept as opposed to a method of instruction. This gives the instructor clues about when a topic needs to be revisited or a student may need more support.

\subsubsection{Forming Customized Instruction}

The process of mass customization in educational terms is based on a demand from a group of learners where the combination of learning materials, learning services, and teaching efforts should fulfill certain explicit or implicit requirements and a supply of building blocks (learning materials, services, and teaching efforts) that can be combined into an offer fulfilling the demand. The resulting offer should comply with several general requirements and potentially there is a significant number of building blocks available. To this end, the institution can meet part of the demand from a learner. Elements like determining the learning goals, adaptation of the learning process based on feedback from the learner, or assessing the level of prior knowledge are not part of this approach (Shoham,2012). Zmuda, Ullman and Curtis (2015) propose three ways to form customized instruction in order to improve learning for students:

-Encourages Self-Analysis: Customized instruction encourages self-analysis in students and help them understand themselves and the world they live in on a deeper and more meaningful level. Self-analysis is an important aspect of learning, which often is very personal; if students are afraid to explore their own minds because of the intimidating environment of a large classroom, they'll suppress their critical thinking ability and rely more on groupthink conclusions.

-Maximizing Potential: Customized instruction maximizes a student's potential by designing the pace of learning and curriculum around their ability to understand and learn. Moreover, customized instruction gives students the time to develop and realize their potential, as they have access to a well-educated teacher who has the time and resources to help them in a way that's effective for them as an individual.

-Fosters Realistic Perceptions: Fostering realistic perceptions is even more important in the modern, technologically-dominated world children are growing up in today. Students in large classrooms and schools can so easily become invisible and create unrealistic perceptions of themselves and the world they live in. Customized instruction fosters realistic perceptions because it cuts through the distractions and holds students accountable to reality. When teachers have the resources and time to pay attention to each child during class, students will be kept on track with their goals and have a more realistic understanding of themselves and the world around them.

Fullan(2009) proposed that customized instruction should be thought of as a pedagogical rather than an organizational set of strategies in order to support the learning process of learners so that each individual learner in the classroom can develop his or her individual capabilities and limitations .Customized instruction involves paying attention to the individual capacities and educational needs of student such as content, level, pace, interest or structure .

Salser (2001). revealed that customized instruction has two forms involving classroom and institutional level. At classroom level customized instruction, student and teachers collaborate to achieve relevant form of 
learning process considering the learners' needs, desires, and preferences and learning styles.

At institutional level, customized instruction is concerned with the allocation of the facilities requiring in creating relevant educational environment with the consideration of the special needs learners who are in the mainstream (Powell and Kusuma-Powell, O. (2011)..

\subsubsection{Characteristics of Customized Instruction}

Bray and McClaskey (2013) proposed that customized instruction requires various points to be considered in the process of implementation:

-Lesson plans, including the goals, teaching style and content, are geared toward the specific needs of the student -Lessons are developed based on the interests of the student

-The pace of teaching is adjusted to suit the individual student: lessons move at the pace of the student's learning -Students have a say over what they learn and how they learn it

-Technology is often used to achieve the goals of personalized learning

-Personalized learning involves developing customized lesson plans that reflect the interests and needs of each student, and it uses technology to help guide individual learning.

\subsubsection{Purpose and Benefits of Customized Instruction}

The purpose of customized instruction is to help every student reach their potential by optimizing their learning experience to suit their particular needs. Its ultimate aim is to ensure every student succeeds academically and it achieves that goal by creating unique lesson plans to challenge and inspire each individual student. (Miliband,2006). Customized instruction benefits both students and educators alike, providing tailored learning experiences for students to pursue their interests at their own pace, and allowing teachers to focus on guidance, support and longer-term planning. Moreover, it entails the involvement of the all dimensions of learner (cognitive, social, emotive); empowerment of awareness of the learning process; development of self-regulated learning process; co-design of the learning pathway and process; development of self-evaluation process; learning challenges instead of learning objectives, and learning pathway instead of instructional curriculum or training program.

Customized instruction is an educational approach that aims to personalize learning for each student's strengths, needs, skills, and interests. Each student gets a learning plan that's based on what they know and how they learn best. Intuitively students learn in different ways and at different paces, so customized instruction model is based on that premise (Rippel, Panchal, Schaefer and Mistree, F. (2009).

Students work with their teachers to set both short-term and long-term goals. This process helps students take ownership of their learning. Teachers make sure learning plans match up with academic standards and they check to see if students are demonstrating the skills they are expected to learn as they progress through their education. Customized instruction is an approach to general education that can work with an Individualized Education Program (IEP. Customized instruction require determination of high expectations for all students and aligns their learning to a set of rigorous standards( Bates, 2005). Thus, the use of learners' profiles are inevitable and they must be kept up-to-date record that provides a deep understanding of each student's individual strengths, needs, motivations, progress and goals. These profiles are updated far more often than a standard report card and these detailed updates help teachers make decisions to positively impact student learning. A learner profile also helps students keep track of their own progress. It gives the teacher, the student and, in many schools, the parent a way to know if they need to change a learning method or make changes to goals - before the student does poorly or fails (Shoham, 2012).

\subsubsection{Personalized Instruction}

Personalized instruction has different meanings and definitions for different practitioners and there are different degrees or stages of personalization. The common sense of various meanings and definitions is that they are based on student-driven learning and teaching. According to Martinez, (1999), the real potential of a personalized approach to learning lies in teachers' exploration of ways to customize curriculum, instruction, and even assessment in ways that differ from person to person, and student to student. According to the U.S. Department of Education, personalization refers to instruction that is paced to learning needs, tailored to learning preferences, and tailored to the specific interests of different learners. In an environment that is fully personalized, the learning objectives and content as well as the method and pace may all vary. Riddett (2015) mentioned that personalized instruction provides the most student autonomy. Students have an active role in designing lessons and projects that are meaningful and relevant to them based on their interests, aspirations, and passions. Teachers, then, act more as guides than the curators of information and learning experiences. Personalized learning is defined as tailoring learning for each student's strengths, needs, and interests including enabling student voice and choice in what, how, when, and where they learn to provide flexibility and support to ensure mastery of the highest standards possible (Leadbeater,2009).Adami, (2004). identified ten essential components of personalization. They are: student agency, differentiated instruction, on-demand and immediate instructional interventions and support for each student, flexible pacing, individual student profiles or learning paths, deeper learning and problem solving, frequent feedback from both instructors and peers, standards-based knowledge and skills, anywhere, anytime 
learning and performance-based assessments. In a personalized learning classroom, students' critical thinking is encouraged and they are tasked with choosing and using the appropriate resources and technological tools necessary for their learning. As students' progress toward their goals, they monitor their own progress and learn to articulate and defend the quality and nature of their learning. The teacher's role is to promote the development of independent learners through assessment which entails model and explicitly teach self-assessment skills, guide students in setting goals and monitoring progress, provide examples of quality work that reflects desired curricular outcomes, guide students in developing internal feedback and self-monitoring strategies to validate and question their own thinking, provide regular and challenging opportunities to practice, so that students gain confidence and create a safe environment for students to take chances and receive support (Adami, 2004). Student's needs are determined by the students and connected to their interests, passions, and aspirations. Students are taught to understand how they learn best so that they can tell their teachers how they would like to acquire information, express what they know, and engage with the content. Students participate in their learning by co-designing their learning objectives and the path they will take to get there. The teacher is positioned as the helpful guide on the side. Students select their own appropriate resources and tools, and build a network of peers, teachers, and experts to support and guide their learning. Students demonstrate mastery and continually self-assess their learning (Coffey,2007). According to the National Educational Technology Plan developed by the US Department of Education, personalized learning is defined as adjusting the pace (individualization), adjusting the approach (differentiation), and connecting to the learner's interests and experiences. Personalization is broader than just individualization or differentiation in that it affords the learner a degree of choice about what is learned, when it is learned and how it is learned (Subban, 2006).

Customized learning experiences essentially shifting the course from teacher-directed to learner-directed and from a course that focuses on content to one that focuses on what students are doing with the content. Boettcher (2010) outlined the nine points of customization that can map neatly to the four phases of any course: the beginning, early middle, late middle, and wrap-up. The nine points are:

Beginning of the course:

1. Get acquainted - Help students get to know other students and personalize their social presence in the course by sharing photos, bios, and interests. This helps lay the foundation of a learning community.

2. Customize learning goals - Create a discussion thread or forum during the first week that requires students to review course goals and outcomes. Find out what the students know and what they want to know once the course is complete.

3. Exam course structure and expectations - Review with your students the course structure, assignments, and expectations for meetings and deadlines to ensure the structure aligns with their needs, expectations, and goals. Early middle of a course:

4. Differentiate assignments and content resources - Build flexibility into your course content that allows you to alter specific assignments based on personal learning goals and readiness.

5. Create options for peer interaction - Team assignments and peer review are powerful community building and assessment tools, but they're not for everyone. Be flexible on how each are used in your course.

6. Build leadership opportunities - Not all learners need to be assessed in identical tasks. Some students may want to lead a seminar or discussion forum, others may prefer to demonstrate their learning through by writing a summary or conducting an interview.

Late middle of a course:

7. Customize and personalize projects - Working adults in particular will proactively work on projects that have meaning for them in other areas of life so it's good to have a project proposal process that cycles between the instructor and the learner for a good learning-interest match.

8. Offer peer review opportunities - Peer review of project proposals, projects-in-process, and finished projects helps build community, extend learning, and reduce grading burdens and unwelcome surprises.

Course Wrap-up:

9. Provide choices for project sharing - End-of-course wrap-ups often include project presentations, allow your students to select from a range of project types, including podcasts, wikis, journals, interviews, papers, etc.

\subsubsection{Differentiated Instruction}

Differentiated instruction is a pedagogical-didactical approach that provides teachers with a starting point for meeting students' diverse learning needs. Differentiated instruction in the classroom entails two aspects. First is the pedagogy and didactics of differentiated instruction: which teaching practices and techniques do teachers use and what do they differentiate (Zmuda, Ullman, and Curtis,2015). Differentiation is a philosophy of teaching rooted in deep respect for students, acknowledgment of their differences, and the drive to help all students thrive. Such ideas imply that teachers proactively modify curricula, teaching methods, resources, learning activities, or requirements for student products to better meet students' learning needs (Tomlinson, 2003). Powell and KusumaPowell (2011) stated several criteria were used to conduct differentiated instruction in primary education. Differentiation is a type of learning where instruction is tailored to meet the learning needs, preferences and goals 
of individual students. Moreover, it is an awareness of and active response to students' varied learning styles. It involves exercising flexibility in assessment, grouping and instruction to create the best learning experience possible. Muijs and Reynolds (2005) contended that differentiation is the modification of four curriculum related element: content, process, product, and affect which are based on three categories of student needs and variance, readiness, interest, and learning profile:

Content: what knowledge and skills do students need to learn

Process: how students learn or understand the content

Product-how students demonstrate their understanding

Affect: how students' disposition impacts learning

Readiness: how currently equipped a student is for learning specified content

Tomlinson (2000 ) explicitly distinguish "readiness" from "ability", saying that "readiness" is temporary, not ingrained.

-Interest: topics, activities, etc. that engage and motivate a student

-Learning Profile: a student's preference for what is learned, how it's learned, and how it's expressed.

The ${ }^{3}$ four ways to differentiate instruction are content, process, product, and learning environment.

3-1. Content: Fundamental lesson content should cover the standards of learning set by the school district or state educational standards.

2. Process: Each student has a preferred learning style, and successful differentiation includes delivering the material to each style: visual, auditory and kinesthetic, and through words. This process-related method also addresses the fact that not all students require the same amount of support from the teacher, and students could choose to work in pairs, small groups, or individually.

Examples of differentiating the process:

Provide textbooks for visual and word learners.

Allow auditory learners to listen to audio books.

Give kinesthetic learners the opportunity to complete an interactive assignment online.

3. Product: The product is what the student creates at the end of the lesson to demonstrate the mastery of the content. This can be in the form of tests, projects, reports, or other activities. You could assign students to complete activities that show mastery of an educational concept in a way the student prefers, based on learning style.

Examples of differentiating the end product:

Read and write learners write a book report.

Visual learners create a graphic organizer of the story.

Auditory learners give an oral report.

Kinesthetic learners build a diorama illustrating the story.

4. Learning environment: The conditions for optimal learning include both physical and psychological elements. A flexible classroom layout is key, incorporating various types of furniture and arrangements to support both individual and group work. Psychologically speaking, teachers should use classroom management techniques that support a safe and supportive learning environment.

Examples of differentiating the environment:

Break some students into reading groups to discuss the assignment.

Allow students to read individually if preferred.

2.1.7 Individualized Instruction

Individualized Instruction calibrated to meet the unique pace of various students is known as ${ }^{4}$ individualized learning and it is based on the learning needs of students and it places more focus on student pacing (Burton,20030.Gottlieb, (2006) stated proposed that differentiation and individualization are distinct, they can be part of the same strategy.

An individualized classroom can differentiate based on individual needs or based on small groups of learners. But whether the learning is differentiated or not, individualized learning allows students to move through the course at their own pace. Tomlinson (2000) stated that this teaching approach, which aims for inclusion, has to be "carefully aligned with essential learning outcomes; informed by ongoing assessment; responds to student readiness, interest, and learning profile uses flexible grouping based on thoughtfully balanced individual, smallgroup, and whole-class work; and ensures that all students have respectful tasks. ${ }^{4}$ Individualized instruction is where students' personal needs are placed at the forefront of an instructor's teaching practices. Content and pace of learning depend on the abilities of individual students in a class. Russell (1998). proposed five steps to individualization in the classroom include: setting clear and specific goals;

4-Individualized instruction involves three elements of the learning process based on the abilities and interests of the student: Content, learning technology and pace of learning. The teaching methods and learning strategies that are important to facilitate individualized instruction involves the nine elements of individualized learning: 
Research of effective teaching techniques; Relevant student data; Knowledge of the curriculum ; Learning delivered at a timely pace; Mapping student progress ; Goals are identified by the student, Available tools can be tailored to individual needs; Continuous conversational feedback, and Engage and collaborate within the Learning Community.

making goals challenging and realistic, making goals dynamic and review regularly, letting students own their progress, and involving parents or academic advisors when necessary.

\subsection{Scaffolding Strategy}

The term 'scaffolding' comes from the works of Wood, Bruner and Ross (1976) and it was developed as a metaphor to describe the type of assistance offered by a teacher or peer to support learning. In the process of scaffolding, the teacher helps the student master a task or concept that the student is initially unable to grasp independently. The teacher offers assistance with only those skills that are beyond the student's capability (McKenzie, 2000). Scaffolding is actually a bridge used to build upon what students already know to arrive at something they do not know. If scaffolding is properly administered, it will act as an enabler, not as a disabler (Hartman, 2002).Scaffolding is a teaching strategy originates from Lev Vygotsky's sociocultural theory and his concept of the ${ }^{4}$ zone of proximal development (ZPD). It provides scaffolds or supports to facilitate the learner's development. The scaffolds facilitate a student's ability to build on prior knowledge and internalize new information. The activities provided in scaffolding instruction are just beyond the level of what the learner can do alone (Van de , Volman and Beishuizen, 2010). Vygotsky defined scaffolding instruction as the "role of teachers and others in supporting the learner's development and providing support structures to get to that next stage or level" (Raymond, 2000, p. 176). An important aspect of ${ }^{5}$ scaffolding instruction is that the scaffolds are temporary. As the learner's abilities increase the scaffolding provided by the more knowledgeable other is progressively withdrawn.

4- The zone of proximal development is the distance between what children can do by themselves and the next learning that they can be helped to achieve with competent assistance" (Raymond, 2000, p.176). The scaffolding teaching strategy provides individualized support based on the learner's ZPD (Chang, Sung, \& Chen, 2002).

Finally the learner is able to complete the task or master the concepts independently (Jaramillo,1996).

McKenzie(2000) mentioned that ${ }^{5}$ scaffolding is a way to provide support for students by breaking learning down into manageable chunks as they progress toward stronger understanding and ultimately greater independence. He listed ten ways to scaffold learning for students:

- Give mini-lessons: Break new concepts down into bite-sized pieces that build on one another. Teaching a series of mini-lessons provides students with a safety net that moves them progressively toward deeper understanding.

- Model/demonstrate: Show your students an example of what they will be learning. For example, demonstrate a science experiment so they can see how it's done before they do it themselves. Or gather them on the rug and let them watch you solve a math problem in a new way.

-Describe concepts in multiple ways: Support different learning styles by approaching new concepts from multiple angles. Show them, tell them, and let them try it for them. The more ways you approach learning, the more sense it will make for students.

- Incorporate visual aids: Show a video, pass out colorful images, or provide a concrete object to start off a new lesson.

-Give students talk time: Be sure to give students plenty of time to process new information by partnering them up or breaking into small groups and let them articulate concepts in their own words to one another.

- Give students time to practice: After you model learning for your students, take some time to practice with them and have a few students come up to the board and try a math problem.

5- Therefore the goal of the educator when using the scaffolding teaching strategy is for the student to become an independent and self-regulating learner and problem solver. As the learner's knowledge and learning competency increases, the educator gradually reduces the supports provided. (Hartman, 2002).

-During lessons, check for understanding: Check in often to make sure students are with you.

- Activate prior knowledge: Show students the big picture and make connections to concepts and skills students have already learned.

- Front-load concept-specific vocabulary: Arm students with specific academic language they will need to understand ahead of time so that vocabulary doesn't become a stumbling block to higher level learning.

- Set them up for success: Students perform better when they fully understand what is expected of them, so describe the purpose of the assignment, and give them concrete examples of the learning goals they are expected to achieve. Moreover, give the students clear directions and show them exemplars of high quality work. Finally, provide them with a rubric so they know exactly what to do to successfully master the concept.

\section{2 .1 Scaffolding in Educational Setting and Customized Instruction}


In the educational setting, scaffolds may include models, cues, prompts, hints, partial solutions, think-aloud modeling and direct instruction (Hartman, 2002).

The scaffolds provided are activities and tasks that: motivate or enlist the students' interest related to the task; simplify the task to make it more manageable and achievable for students; provide some direction in order to help the child focus on achieving the goal; clearly indicate differences between the child's work and the standard or desired solution; reduce frustration and risk; and model and clearly define the expectations of the activity to be performed (Cavanagh, 2014). Toth(2002) stated that scaffolding delivers efficiency, creates momentum through the structure provided by scaffolding and students spend less time searching and more time on learning and discovering, resulting in quicker learning.

According to McKenzie (2000) scaffolding provides clear direction and reduces students' confusion ; clarifies purpose which helps students understand why they are doing the work and why it is important; keeps students on task by providing structure; the scaffolded lesson or research project; provides pathways for the learners; clarifies expectations and incorporates assessment and feedback; points students to worthy sources ; and reduces uncertainty, surprise, and disappointment. Moreover, scaffolded instruction is also employed in ${ }^{6}$ problem based learning environments.

One of the primary benefits of scaffolding instruction is that it engages the learner. The learner does not passively listen to information presented instead through teacher prompting the learner builds on prior knowledge and forms new knowledge. In working with students who have low self-esteem and learning disabilities, it provides an opportunity to give positive feedback to the students (Riddett, 2015). However, this is also the biggest disadvantage for the teacher since developing the supports and scaffolded lessons to meet the needs of each individual would be extremely time-consuming ( Gottlieb, 2013).

6-Problem-based learning (PBL) is an educational approach that challenges students to "learn to learn".In this type of classroom the teacher must assess the activities that the students can perform independently and what they must learn to complete the task. The teacher designs activities which offer just enough of a scaffold for students to overcome this gap in knowledge and skills (Himmele and Himmele, 2009).

Crucial to successful scaffolding is an understanding of the student's prior knowledge and abilities. The teacher must ascertain what the student already knows so that it can be connected to the new knowledge and made relevant to the learner's life, thus increasing the motivation to learn and many different facilitative tools can be utilized in scaffolding student learning. Among them are: breaking the task into smaller, more manageable parts; using 'think aloud, or verbalizing thinking processes when completing a task; cooperative learning, which promotes teamwork and dialogue among peers; concrete prompts, questioning; coaching; cue cards or modeling (McKenzie, 2000). Hartman (2002) states that there are two major steps involved in instructional scaffolding: development of instructional plans to lead the students from what they already know to a deep understanding of new material and execution of the plans, wherein the instructor provides support to the students at every step of the learning process.

There are a number of benefits to scaffolding instructional approaches in the classroom. Some of these benefits are related to the fact that they have a personal, emotional impact on students. Other benefits to scaffolding include the positive outcomes in grades. Here are just some of the ways that scaffolding can benefit students. Furthermore, it creates a more positive classroom and it helps reduce frustration and anxiety in the classroom (Bray and McClaskey,2015). Scaffolding creates a supportive environment with higher levels of engagement between students, teachers, and their peers. Using scaffolding brings together a number of positive practices associated with improved academic outcomes, including peer learning and increased teacher support. Scaffolding creates a more easygoing classroom with a much more supportive structure in which students don't have to stress themselves out about how well they do. This approach makes it easier to encourage student innovation and participation and lessons the anxieties students feel about coming to class. Every student has one particular subject that they don't feel confident about, and scaffolding can remove the negative perceptions they might have of those classes (Pipkin, 2015).

\section{2 .2 Features of Scaffolding}

In an appropriate scaffolding process, there will be specific identifiable features that are in place to allow facilitation of assisting the learner in internalizing the knowledge until mastery occurs. Pipkin (2015) identify these five features as:

-Intentionality: The task has a clear overall purpose driving any separate activity that may contribute to the whole. -Appropriateness: Instructional tasks pose problems that can be solved with help but which students could not successfully complete on their own.

-Structure: Modeling and questioning activities are structured around a model of appropriate approaches to the task and lead to a natural sequence of thought and language (Dixon, , Yssel, , McConnell, and Hardin, 2014)..

-Collaboration: The teacher's response to student work recasts and expands upon the students' efforts without rejecting what they have accomplished on their own. The teacher's primary role is collaborative rather than 
evaluative.

-Internalization: ${ }^{7}$ External scaffolding for the activity is gradually withdrawn as the patterns are internalized by the students. Zmuda, Ullman and Curtis (2015) stated six general elements of scaffolded instruction:

7- McKenzie(2000) stated there are five different methods in instructional scaffolding: modeling of desired behaviors, offering explanations, inviting students to participate, verifying and clarifying student understandings, and inviting students to contribute clues. These techniques are used to direct students toward self-regulation and independence. In addition, there are three types of modeling: Think-aloud modeling gives auditory substance to the thought processes associated with a task. For example, a teacher might verbalize her thought processes for breaking an unfamiliar word down into its parts so that it can be read; Talk-aloud modeling involves verbalizing the thought process or problem-solving strategy while demonstrating the task. An example would be a teacher verbally describing her or his thought processes as hel she demonstrates the correct way to subtract two-digit numbers on the board. Lastly, there is performance modeling; and Performance modeling requires no verbal instruction. For example, a baseball coach might show one of his players how to get under a ball to catch it.

- Sharing a specific goal: It is the teacher's responsibility to establish the shared goal. The teacher must do some pre-assessment of the student and the curriculum

- Achievement of curriculum objectives is planned as the teacher considers the needs of each student. The teacher must be considerate of some of the unique, unusual, and often ineffective problem-solving techniques that children use. Allowing input from the student on the shared goal will enhance intrinsic motivation.

-Whole task approach: In the whole task approach, the focus is on the overall goal to be attained throughout the entire process. Consequently, the task is learned as a whole instead of a set of individual sub-skills. Each feature of the lesson is learned as it relates to the whole task. This approach lessens the amount of passive knowledge on the part of the learner and the need for transfer is not as great. It must be noted that this approach is only effective if the learner does not experience extreme difficulty with any of the component skills needed to complete the whole task

-Immediate availability of help: Frequent success is important in scaffolding, especially in helping control frustration levels of the learner. Increasing motivation through a positive self-efficacy and make the learner's time and effort more productive (McKenzie, 2000).

- Intention-assisting: It is central to the scaffolding process to supply assistance to the learner's present focus, thereby helping the learner with his/her current difficulties. In providing this immediate help with the current task at hand, a more productive learning environment is fostered because information has been related and conferred according to the learner's focus keeping the learner in pursuit of the task.

- Optimal level of help: What the learner is able to do should be matched with the level of assistance provided. The learner should be given just enough help to overcome the current obstacle, but the level of assistance should not hinder the learner from contributing and participating in the learning process of that particular task. In other words, the assistance should only attend to the areas of the task that he/she cannot accomplish on his/her own.

-Conveying an expert model: An expert model can provide an explicit example of the task as the expert way of accomplishing the task. The techniques for accomplishing the task are clearly expressed. In an implicit demonstration, the information is outlined around the expert model.

According to Miliband (2006) distributed scaffolding are of three types:

Differentiated scaffolding- the basic type which can be most effectively used to recall the previously learnt or make connections between the previously learnt concepts. This can be an activity designed which involves all the previously learned or picture based. Some numeracy games or vocab games, poems or literary activities can also be used in this case; redundant scaffolding - the current learning topic or the learning outcome focus should be provided with a number of support work which may include document reference, research work, project work, assignments on the same topic of learning; synergetic ${ }^{8}$ scaffolding - a complete view of the topic to be provided can be given using different type of approach to the same problem. North Illinois University recommends a fourstage method of scaffolding progresses from teacher led activity to independent learning. In the first stage, an instructor introduces the subject and performs a task related to that subject. During this period, they connect previously learned material to material that is about to be introduced and show how a newly learned task can be completed. This is a period that allows students to observe and later model the teacher's behavior. Afterward, the teacher can ask for the class as a

8- Scaffolding is used in a very wide range of situations. Mothers naturally employ this approach as they teach their children how to live in and enjoy their world. Teachers, from Pre-Kindergarten to Adult Education appreciate the necessity and increased learning afforded by the use of these techniques. The scaffolding should be removed gradually and then removed completely when mastery of the task is demonstrated.

whole to participant in completing a similar activity. During this time, the teacher takes feedback from the class about what to do next when completing the task. Some activities may lend themselves to the teacher writing a list of these recommendations and trying out each of them. Regardless of whether a list can be created, the third 
step of the lesson involves bringing groups together to complete a similar activity. In groups, students can work together and use peer instruction to help guide each other through the activity. The last stage of the lesson involves teachers allowing students to complete a similar task on their own. At this stage, the teacher removes the scaffolding entirely and allows the students to work independently. Building on the knowledge they've gained over the three previous stages, they can more effectively tackle a similar problem independently. Of course, even with a four-stage process, some students may not have fully grasped the lesson. This fourth stage is an important point in which teachers can assess student progress but also determine how effective their scaffolding process was.Van de , Volman and Beishuizen(2010) state that there are two major steps involved in ${ }^{9}$ instructional scaffolding: development of instructional plans to lead the students from what they already know to a deep understanding of new material," and execution of the plans, wherein the instructor provides support to the students at every step of the learning process.

9-The instructor needs to offer explanations which should openly address the learner's comprehension about what is being learned, why and when it is used, and how it is used. At the beginning, explanations are detailed and comprehensive and repeated often. As the learner progresses in his knowledge, explanations may consist of only key words and prompts to help the learner remember important information. Each facilitative method used is chosen as an individually tailored instructional tool. Teachers have to have open dialogue with the students to determine how they are thinking to clear up misconceptions and to individualized instruction (Subban, 2006).

Scaffolding provides learners with adjustable and temporal support to facilitate internalization of the knowledge needed to complete the task. This support is weaned gradually until the learner is independent and it has three essential features that facilitate learning: The interaction between the learner and the expert; Learning should take place in the learner's zone of proximal development; Scaffolding is the support and guidance provided by the expert, is gradually removed as the learner becomes more proficient (Holton and Clark, 2006). Sawyer (2006) states that scaffolding is characterized by contingency, fading, and transfer of responsibility and it is widely considered to be an essential element of effective teaching as all teachers almost certainly use various forms of instructional scaffolding in their teaching. In addition, it is often used to bridge learning gaps which is the difference between what students have learned and what they are expected to know and be able to do at a certain point in their education. Scaffolding provides learners with adjustable and temporal support to facilitate internalization of the knowledge needed to complete the task. This support is weaned gradually until the learner is independent and it has three essential features that facilitate learning: The interaction between the learner and the expert; Learning should take place in the learner's zone of proximal development; Scaffolding is the support and guidance provided by the expert, is gradually removed as the learner becomes more proficient (Holton and Clark, 2006).

One of the main goals of scaffolding is to reduce the negative emotions and self-perceptions that students may experience when they get frustrated, intimidated, or discouraged when attempting a difficult task without the assistance, direction, or understanding they need to complete it (Wise and O'Neill, 2009).

\subsubsection{Types of Scaffolding}

Rosenshine and Meister (1992) categorized scaffolding into four ${ }^{1}$ types:

-Procedural scaffolding helps learner use appropriate tools and resources effectively. Besides, it is also supports learning on how to navigate the course environment and engage in learning activities. of the course and how to navigate the course environment.

-Conceptual Scaffolding helps learner decide what to consider in learning and guide them to key concepts. Conceptual scaffolding guides the learner regarding what to consider during learning.

-Strategic Scaffolding helps learner find alternative strategies and methods to solve complex problems. It emphasizes alternative learning pathways and tailored instruction to support individual students. Besides, strategic scaffolding also requires an understanding of the individual learning preferences of learners and level of prior knowledge. This kind of scaffolding also may require strategies to help simplify and organize information and requires frequent dialogue with student.

-Meta cognitive Scaffolding supports learner in developing thinking and manage their learning. This scaffolding prompts students to think about what they are learning throughout the process and assists students reflecting on what they have learnt (self-assessment). Generally, metacognitive scaffolding can be divided into categories that encourage students' metacognition in learning.

1-Silliman and Wilkinson (1994) distinguish two types of scaffolding: supportive scaffolding that characterizes the IRF (Initiation-Response-Follow-up) pattern; and directive scaffolding that refers to IRE (Initiation-ResponseEvaluation). Saxena (2010) develops these two notions theoretically by incorporating Bhaktin's (1981) and van Lier's (1996) works. Within the IRE pattern, teachers provide directive scaffolding on the assumption that their job is to transmit knowledge and then assess its appropriation by the learners. The question-answer-evaluation sequence creates a predetermined standard for acceptable participation and induces passive learning. In this type of interaction, the teacher holds the right to evaluate and asks known-information questions which emphasize the reproduction of information (Nassaji and Wells, 2000). 
According to Iris Tabak: Distributed Scaffolding are of three types:

-Differentiated scaffolding - The basic type which can be most effectively used to recall the previously learnt or make connections between the previously learnt concepts. This can be an activity designed which involves all the previously learned or picture based. Some numeracy games or vocab games, poems or literary activities can also be used in this case.

-Redundant scaffolding - The current learning topic or the learning outcome focus should be provided with a number of support work which may include document reference, research work, project work, assignments on the same topic of learning.

-Synergetic scaffolding - A complete view of the topic to be provided can be given using different type of approach to the same problem. Changing variables is one such approach. Giving problems which may ultimately lead to same solution is also one approach. For example - Increase in health issues during rain, Change in color of marble wall, change in drinking water color, skin burns during rain can all focus on one major issue of Pollution.

\subsubsection{Challenges and Benefits of Scaffolding}

Lipscom and West (2010) list the following challenges of scaffolding:

-Very time consuming

-Lack of sufficient personnel

-Potential for misjudging the zone of proximal development; success hinges on identifying the area that is just beyond but not too far beyond the students' abilities

-Inadequately modeling the desired behaviors, strategies or activities because the teacher has not fully considered the individual student's needs, predilections, interests, and abilities (such as not showing a student how to "double click" on an icon when using a computer)

-Full benefits not seen unless the instructors are properly trained

-Requires the teacher to give up control as fading occurs

-Lack of specific examples and tips in teacher's editions of textbooks

Lai and Law (2006). state the following benefits of scaffolding:

-Provides individualized instruction

- ${ }^{1}$ Greater assurance of the learner acquiring the desired skill, knowledge or ability

-Provides differentiated instruction

-Delivers efficiency - Since the work is structured, focused, and glitches have been reduced or eliminated prior to initiation, time on task is increased and efficiency in completing the activity is increased.

-Creates momentum - Through the structure provided by scaffolding, students spend less time searching and more time on learning and discovering resulting in quicker learning

Morelock, Brown and Morrissey (2003) noted in their study that mothers adapt their scaffolding to the perceived abilities of their children. The mothers scaffold interactions at play by modeling or prompting behaviors which they see demonstrated by their child or just beyond the level demonstrated. For instance, the very young child is playing with blocks by stacking them on top of each other.The mother attracts the child's attention and models how to "build" a wall or bridge by stacking them in a different way and using a toy person or truck to climb the wall or ride over the bridge. She then watches and assists as needed until the child appropriates the skill or loses interest and moves on to something else. She will try again the next time the child is playing with the blocks or try another construction which she feels will be more attractive to the child

-Engages the learner

-Motivates the learner to learn

-Minimizes the level of frustration for the learner

\subsection{Learning English in Saudi Arabia Context}

Teaching English language in Saudi Arabia context is shaped by various factors such as the involvement of Arabic language interference in terms of code switching (Nouraldeen and Elyas,2014); excluded westernized culture in terms of colonization (Tanveer ,2007) ; lacking of authenticity; lacking of suitable English language exposure; teacher-centricity (Khan, 2011); lacking of learners' involvement in class discussion and decision making; rote learning based, over-reliance on teachers and the spoon-feeding nature of instruction prevalent in this context(Al-Johani, 2009); syllabus design is based on the reflection of its designers' personal perceptions and intuitions rather than on students' actual needs, goals, desires, and real-life concerns(Al-Subahi 1991). Alhammad (2010) claimed that the academic approaches at Saudi schools encourage students to develop a system of ineffective memorization and a superficial understanding of facts for the sole purpose of passing exams rather than achieving deep and meaningful learning. Further support to this claim comes from Al Alhareth and Al Dighrir's (2014) research revealing that the Saudi education system focusses on subjects that do not appeal to stu-dents, and that the reliance on rote learning leads to memorisation rather than understanding.

Alkahtani (2011) examined Saudi EFL college ${ }^{10}$ students' preferred learning styles as a predictor of academic 
persistence, satisfaction, and success in different learning environments. The preferred experiences, and their learning style preferences. The study's findings revealed further that the learning styles of Saudi EFL learners are determinants of their language learning strategy choice, motivation, and confidence.

10 The majority of Saudis have held negative attitudes about English in the past; however, it has been a noticeably positive shift in Saudi learners' attitudes towards English in recent years. Hence, Saudi learners have a great desire and motivation to learn English and speak English due to various instrumental motivational factors, social factors and subjective factors.

This study emphasized the importance of understanding Saudi students' learning styles and meeting their expectations and needs in the classroom. Alrashidi and Phan (2015) have proposed that the teacher is perhaps the strongest determinant of learners' motivation, and have attributed Saudi EFL learners' low motivation to lack of proper teacher encouragement and support. As Al-Johani (2009) has pointed out, teachers commonly fail to provide encouragement to their learners and/or to acknowledge learners' participation and ideas; they often fail to offer examples from real life situations when presenting lessons.

\subsection{Method of the Research 3.1Introduction}

The method used to conduct this study was the descriptive research method. A questionnaire was designed and used for data collection. The researcher used Microsoft Office Program for analyzing the data. The collected data was transformed into figures and tables to facilitate interpretation.

\subsection{Subjects}

The population used in this study, was chosen randomly from the English language teachers of Aseer Schools, KSA. It consisted of forty-five teachers of remarkable English language teachers, who were teaching English language through the customized instruction method in the school year 2020.

The instrument, which was used as a data-collecting tool, were a questionnaire and the researcher's observation. The questionnaire included twenty-five items in order to attain the objectives and the aims of the study.

\subsection{Validity}

After the researchers designed the questionnaire, they conducted a pilot survey. In the light of the survey, some modifications were made to the questionnaire. The questionnaire was sent through e-mail to a number of judges, so it was revised and modified in the light of the comments and suggestions made by the judges. They were from KKU. They expressed their opinions by making certain omissions, additions and modifications. Some of the statements were rephrased for the sake of clarity and comprehension. They agreed on all the statements of the questionnaire after reassessment and modifications were made. According to observation of the judges, the questionnaire was valid and all its items were accurate. In order to show the appropriateness and the effectiveness of the tool used for data collection in the present study, some experts were asked to check to what extent the items of the questionnaire were suitable in terms of instructions, the types of items and their suitability to the subjects, the style and the language used in the tools, the illegibility of the items and any other comments. The questionnaire was checked and examined by experts from the Department of English, College of Languages and Translation, King Khalid University, before it was distributed for teachers to fill.

\subsection{Participant}

The selection of the sample was done randomly by taking 45 school teachers from the target population. They were chosen from Asser area to participate in this study. Their experiences ranged between $(5 / 20)$ years. They were males teachers.

\subsection{Reliability}

To determine the reliability of the questionnaire, the researchers administered the questionnaire to forty-five English language teachers in Abha Schools. The reliability of the whole questionnaire can be estimated by using the formula:

$\mathrm{R}=1-\frac{6 \sum_{d} 2}{n\left(n^{2}-1\right)} . \quad$ Where $\mathrm{R}=$ reliability $\quad \mathrm{D}=$ difference $\mathrm{N}=$ number of individuals. 
Table 1 . The reliability of the Questionnaire.

\begin{tabular}{lllll}
\hline $\mathrm{X}$ & $\mathrm{Y}$ & $\mathrm{XY}$ & $\mathrm{d}$ & $\mathrm{D}^{2}$ \\
\hline 1 & 2 & 2 & 1 & 1 \\
3 & 4 & 12 & 1 & 1 \\
5 & 6 & 30 & 1 & 1 \\
7 & 8 & 56 & 1 & 1 \\
9 & 10 & 90 & 1 & 1 \\
11 & 12 & 132 & 1 & 1 \\
13 & 14 & 172 & 1 & 1 \\
15 & 16 & 240 & 1 & 1 \\
& & & & 8 \\
\hline
\end{tabular}

$\mathrm{R}_{1}-1=\frac{6 * 8}{50\left(50^{2}-1\right)}=1-\frac{48}{124950}=0,99$

The spearman formula was used to make the $\mathrm{CO}$ efficient of reliability for the whole unit=

\section{$2 *$ coefficientofreliabiltyo fthefirsthalf}

$1+$ coefficietofthereliabiltysecondhalf

$$
\mathrm{R}=2 * \frac{0,99}{1+0,99}=0,9
$$

The result obtained is 0,9 which means that the questionnaire is reliable and consistent.

0,95 where $\mathrm{V}=$ the validity, $\mathrm{R}=$ the reliability $=\sqrt{0,9}=\mathrm{V}=\sqrt{R}$

Procedure of data analysis 3.3

\subsection{Procedure and Data Collection Tool}

The selected tool for this study is a questionnaire for 45 secondary school teachers. The questionnaire was prepared and distributed to ELT teachers in Aseer area; it was made up of 25 multiple choice items. The items were arranged in the logical progression depending on the hypotheses of the study, the data were calculated manually, then analyzed by the computer, with the program (SPSS) Statistical Package for Social Sciences.

The questionnaire was given by hand to the sample. They responded by putting a tick in the appropriate space opposite to an item in one of the following choices: strongly agree, agree, neutral, disagree and strongly disagree. After that 'strongly agree' and 'agree' were summed up and 'disagree' and 'strongly disagree' were summed up. The responses became only three columns: agree, neutral and disagree. These three responses were given values as 'excellent', 'v. good', and 'good'. The responses below 'good' were rejected. According to the scale, which was designed by the researcher, the general mean was (3.31).

\subsection{Data Analysis and Discussion}

\subsection{Results of the Students' Questionnaire}

To answer the first questions of the research, means and standard deviation were calculated for the implementation of customized instruction in Saudi Arabia's schools.

\subsection{Results of the Students' Questionnaire}

To answer the first question of the research, means and standard deviation were calculated for the implementation of customized instruction efficiency in Saudi Arabia schools. The first domain was related to the implementation of customized instruction in English class, the second domain was related to the teachers' role in teaching English using customized instruction, and finally, the third domain was related to the impact of the implementation of scaffolding in teaching English. 
Table (1) The Domains of the Questionnaire

\begin{tabular}{|l|l|l|l|l|}
\hline Domains & Mean & $\begin{array}{l}\text { Std. } \\
\text { Deviation }\end{array}$ & Rank & Degree \\
\hline $\begin{array}{l}\text { The implementation of customized instruction efficiency in English } \\
\text { class }\end{array}$ & 3.34 & 0.47 & 1 & moderate \\
\hline The teachers' role in teaching English using customized instruction & 3.31 & 0.45 & 2 & moderate \\
\hline The impact of the implementation of scaffolding in teaching English.3.33 & 0.46 & 3 & moderate \\
\hline
\end{tabular}

The findings of Table (1) shows that the implementation of customized instruction in English class, the teachers' role in teaching English using customized instruction and the impact of the implementation of scaffolding in teaching English came in moderate degree with a total mean of (3.31) and standard deviation of (0.42), Therefore; all the domains came in moderate degree. This confirms that the implementation of customized instruction facilitates learning process because it satisfies the learners' needs, preferences and considers the learners' styles of learning. Moreover, it confirms that scaffolding assists the learners construct knowledge and they learn how to learn from autonomous learning perspective.

Table (4) shows means and standard deviation for the first domain:

Table (2)Means, Standard Deviation, Ranks and Degree of the Questionnaire Items

\begin{tabular}{|c|c|c|c|c|c|}
\hline No. & Questionnaire Item & Mean & $\begin{array}{l}\text { Std. } \\
\text { Deviation }\end{array}$ & Rank & degree \\
\hline 4 & $\begin{array}{l}\text { Implementation of customized learning and scaffolding } \\
\text { convert learning habits among students such as over reliance } \\
\text { on translation }\end{array}$ & 3.05 & 0.97 & 1 & Moderate \\
\hline 3 & The students adapt to customized instruction gradually & 2.91 & 0.99 & 2 & Moderate \\
\hline 5 & $\begin{array}{l}\text { Implementation of customized and scaffolding creates } \\
\text { friendly social educational atmosphere }\end{array}$ & 2.71 & 0.87 & $\beta$ & Moderate \\
\hline 2 & $\begin{array}{l}\text { In my classroom, implementation scaffolding raises } \\
\text { comprehension rate among students }\end{array}$ & 2.52 & 0.87 & 4 & Moderate \\
\hline 6 & $\begin{array}{l}\text { In my classroom, implementation customized instruction } \\
\text { enhances learning process }\end{array}$ & 2.22 & 0.82 & 5 & Moderate \\
\hline 1 & $\begin{array}{l}\text { In my class, implementation customized instruction } \\
\text { satisfies learners' needs and preferences }\end{array}$ & 2.21 & 0.85 & 6 & Moderate \\
\hline
\end{tabular}

Table (2) shows that item (4) which states "Implementation of customized learning and scaffolding convert learning habits among students such as over reliance on translation" with a mean of (3.05) and (0.97) standard deviation, came in the first rank. "The students adapt to customized instruction gradually" in second rank with a mean of (2.91) and a standard deviation of (0.99). In the third rank came item (5) and it states "Implementation of customized and scaffolding creates friendly social educational atmosphere" with a mean of (2.71) and a standard 
deviation of (0.87). In the last rank came item (1) which states " In my class, implementation customized instruction satisfies learners' needs and preferences" with a mean of (2.21) and a standard deviation of (0.99).

Table (3)

\begin{tabular}{|l|l|l|l|}
\hline Answer & Frequency & Percent & Value \\
\hline Agree & 691 & 61.4 & 3081 \\
\hline Neutral & 146 & 13.0 & 438 \\
\hline Disagree & 288 & 25.6 & 497 \\
\hline Total & $\mathbf{1 1 2 5}$ & $\mathbf{1 0 0 . 0}$ & \\
\hline
\end{tabular}

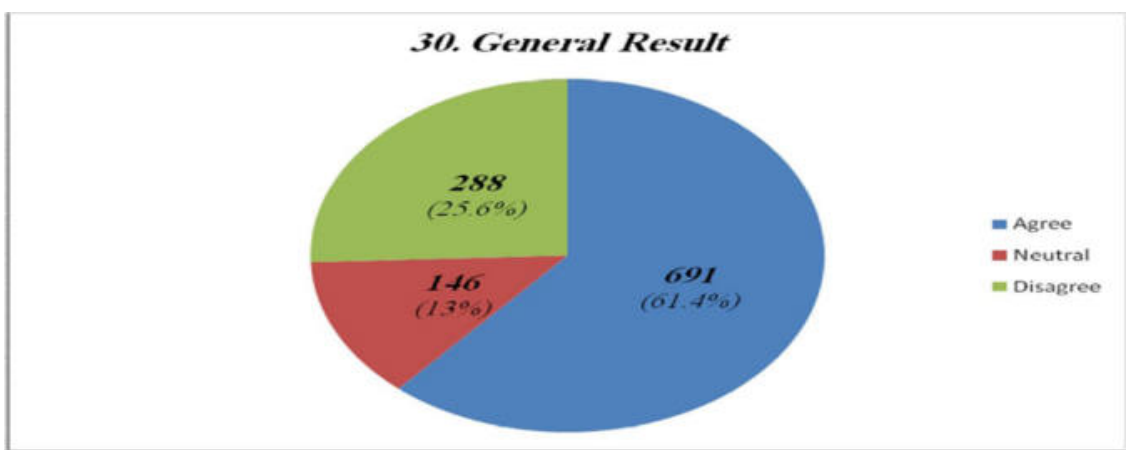

Table (3) represents the general results of all items of the questionnaire. The table and pie chart (30) illustrate that more than $60 \%$ of the respondents responded, "agree', $13 \%$ of the respondents were neutral and $25.6 \%$ of the respondents responded "disagree". The largest piece of the pie represents agreed respondents.

The total number of the frequencies was $\mathbf{1 1 2 5}$. Only $\mathbf{2 8 8}$ of the frequencies disagreed and one hundred and forty- six (146) of the frequencies were natural. The biggest number was 691, "agree" responses. Those numbers indicate that there are difficulties in the use of interactive whiteboard in the English language classes.

\subsection{Conclusion}

5.1 Summary

Based on data analysis, most of Aseer Schools' English language teachers implementing customized instruction and scaffolding in their classes notice that various progress in learning English such increase interactivity, confidence, comprehension, good performance in terms of tasks, learners' satisfaction in terms of needs and teachers need more training on customized instruction. The study recommends that teachers need continuing pedagogical training on using customized instruction and scaffolding.

\subsection{Findings}

The findings of this study show many positives sides of implementation customized instruction and scaffolding:

1- Implementation customized instruction and scaffolding facilitates learning English and increase comprehension among students.

2- Implementation customized instruction and scaffolding converts teaching from conventional approach (teachercentered approach) into learner - centered approach.

3- Most of English teachers lack pedagogical knowledge and skills about customized instruction and scaffolding.

4- Considering Saudi learners' needs, preferences and learning styles is focal core of learning English language.

5- Implementation customized instruction and scaffolding in English class motivates learners and increases their English productivity in terms of speaking and writing.

6- Most of the Saudi learners taught in customized instruction and scaffolding see learning English simple rather than their prior negative perception toward English.

\subsubsection{Pedagogical Implication}

- English teachers lack pedagogical in-service training in implementing customized instruction and scaffolding strategies.

-Customized instruction and scaffolding strategies facilitate teaching and learning of Saudi learners because they consider their needs and preferences. In addition, it provides them with suitable support and help.

- Implementation of customized instruction and scaffolding tend to be difficult for teachers because they are not accustomed to them.

\subsection{Recommendations}

In the light of these findings the researcher recommends that the implementation of customized instruction and 
scaffolding in English class should be used accurately in order to facilitate teaching and provide fun opportunities for learners to learn English language. The responsibility is shared between educational policy makers, syllabus designers and teachers themselves to integrate the implementation of customized instruction and scaffolding into teaching and learning English language:

1. English teachers should implement customized instruction and scaffolding in their classes.

2. Customized instruction and scaffolding should be implemented in Saudi Arabia. This maximizes students' learning out comes and interactivity.

3.English teachers should prepare themselves for the implementation of customized instruction and scaffolding in their classes, so ongoing pedagogical training on the implementation of customized instruction and scaffolding should be considered seriously.

4.English language teachers should share ideas, resources and experiences to help develop professionally.

5.English teachers should be aware of learners' needs, preferences and their different learning styles. They should be accommodated in English language classes

6. Syllabuses should be transformed to match the learners' needs and preferences from customization perspective.

\subsection{Recommendation for Further Study}

- The Effectiveness of Student Led Education in Facilitating Learning English in Saudi Arabia Context

- The Role of Scaffolding in Teaching Learning Conversation in English Class

- The Effectiveness of Customized Instruction in Minimizing Individual Differences in English Class

- $\quad$ The Overlap between Scaffolding and Noticing Strategy in Learning English Grammar

\section{Acknowledgements}

Special appreciation is due to Asir Schools' English language teachers who participate in this study by responding to the questionnaire and host the researchers in their class. Our gratitude goes to Asir area educational directorate for their collaboration and assistance in facilitating the procedures.

\section{References}

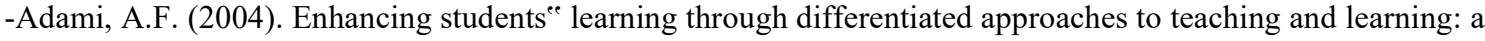
Maltese perspective. Journal of Research in Special Educational Needs, 4, (2), 91-97.

-Alrahaili, M (2014).Predictors of L2 attitudes and motivational intensity: a cross-sectional study in the Saudi EFL context, doctoral thesis, the University of Newcastle, Australia.

-Alrasheed, S (2012) .Exploring the nature of the Saudi English teachers' beliefs and attitudes towards EFL and its effects on their teaching practice', paper presented at the Saudi Scientific International Conference, London, UK, 11-14 October.

-Alshammari, MM (2011).The use of the mother tongue in Saudi EFL classrooms', Journal of International Education Research, vol. 7, no. 4, pp. 95-102, doi: 10.19030/jier.v7i4.6055.

- Bates, A. W. (2005). Technology, e-learning and distance education ( 2 nd $\mathrm{ed}$.). New York, NY: Routledge.

-Berry, A. (2009). Professional self-understanding as expertise in teaching about teaching. Teachers and Teaching: theory and practice, 15, (2), 305-318.

-Burton, D. (2003). Differentiation in schooling and pedagogy. In: S. Bartlett \& D. Burton.(Eds.). Educational Studies: essential issues (pp.42-71). London/Thousand Oaks: SAGE.

-Bray, B., \& McClaskey, K. (2015). Make learning personal: The what, who, how, where, when and why. Thousand Oaks, CA: Corwin.

-Cavanagh, S. (2014). What is personalised learning? Educators seek clarity. Education Week. Available online at: https://www.edweek.org/ew/articles/2014/10/22/09pl-overview.h34.html

- Coffey, S. (2007). Differentiation in theory and practice. In: J. Dillon \& M. Maguire (Eds.).Becoming a teacher: issues in secondary education (third edition, pp.187-201). Berkshire: Open University Press.

-Dixon, F. A., Yssel, N., McConnell, J. M., and Hardin, T. (2014). Differentiated instruction, professional development, and teacher efficacy. J. Educ. Gifted 37, 111-127. doi: 10.1177/0162353214529042

-Hartman, H. (2002). Scaffolding \& Cooperative Learning. Human Learning and Instruction (pp. 23-69). New York: City College of City University of New York.

-Holton, Derek, and Clark, David (2006). Scaffolding and metacognition. International Journal of Mathematical Education in Science and Technology, 37, 127-143.

-Khan, IA (2011). 'Learning difficulties in English: diagnosis and pedagogy in Saudi Arabia', Educational Research, vol. 2, no. 7, pp. 1248-1257.

-Lai, Ming and Law, Nancy (2006). Peer scaffolding of knowledge building through collaborative groups with differential learning experiences. J. Educational Computing Research, 35, 123-144

-Lipscomb, A. Swanson, J. \& West, A.(2010) Emerging Perspectives on Learning, Teaching, and Technology, Global Text, $\quad$ Michael Orey. $\quad$ Chapter $21 . \quad$ Retrieved 
from https://textbookdequity.org/Textbooks/Orey_Emergin_Perspectives_Learning.pdf (CC BY)

-Martinez, M. (1999). Mass customization: A paradigm shift for the 21st century. ASTD Technical Training Magazine, 10 (4), 24-2

-McKenzie, J. (2000). Scaffolding for Success. [Electronic version] Beyond Technology, Questioning, Research and the Information Literate School Community. Retrieved October 12, 2002, from http://fno.org/dec99/scaffold.html

-Mistree, F., Panchal, J. H., \& Dirk Schaefer (2012). Mass-customization: From personalized products to personalized engineering education. In A. Groznik (Ed.), Pathways to supply chain excellence. InTech. Retrieved from http://www.intechopen.com/books/pathways-to-supplychain-excellence/masscustomization-from-personalized-products-to-personalized-engineering-education

-Muijs, D. \& Reynolds, D. (2005). Effective teaching. Evidence and practice.

London/Thousand Oaks/New Delhi: Sage Publications.

-Nouraldeen, AS \& Elyas, T (2014). 'Learning English in Saudi Arabia: a socio-cultural perspective', International Journal of English Language and Linguistics Research, vol. 2, no. 3, pp. 56-78

-Powell, W., \& Kusuma-Powell, O. (2011). How to teach now: Five keys to personalized learning in the global classroom. Alexandria, VA: ASCD

-Rippel, M., Panchal, J. H., Schaefer, D., \& Mistree, F. (2009). Fostering collaborative learning and educational mass customization in a graduate level engineering design course. International Journal of Engineering Education, 25(4), 729-744.Mass Customisation of Education by an Institution of HE: What Can We Learn from Industry? Schuwer and Kusters Vol 15 | No 2 April/14 25

-Rodgers, E. M. (2004). Interactions that scaffold reading performance. Journal of Literacy Research, 36(4), 501532.

-Rosenshine, B., \& Meister, C. (1992). The use of scaffolds for teaching higher-level cognitive strategies. Educational Leadership, 49(7), 26-33.

-Sawyer, R. Keith. (2006). The Cambridge Handbook of the Learning Sciences. New York: Cambridge University Press.

Salser, M. (2001). What is individualized instruction? Portland, Oregon: Educational Research Associates, Inc.

-Smit, R., and Humpert, W. (2012). Differentiated instruction in small schools. Teach. Teach. Educ. 28, 11521162. doi: 10.1016/j.tate.2012.07.003

-Subban, P. (2006). Differentiated instruction: a research basis. Int. Educ. J. 7, 935-947. Available online at: http://ehlt.flinders.edu.au/education/iej/articles/v7n7/Subban/BEGIN.HTM

-Shoham, Y. (2012). Packaged online courses (POCs). Retrieved from http://robotics.stanford.edu/ shoham/www\%20papers/Higher\%20Educated\%20Guesses\%20$\% 20$ Universities.pdf

-Tseng, M., \& Jiao, J. (2001). Mass customization. In G. Salvendy (Ed.), Handbook of industrial engineering (pp. 684-709). New York: Wiley

-Tomlinson, C. A. (2001). How to differentiate instruction in mixed-ability classrooms. Alexandria, VA: Association for Supervision and Curriculum Development.

-Tomlinson, C. A. (2014). The Differentiated Classroom. Responding to the Needs of All Learrners, 2nd Edn. Alexandria, VA: ASCD.

-Tomlinson, C. (2000). Reconcilable differences: Standards-based teaching and differentiation. Educational Leadership, 58, (1), 6-11.

-Tomlinson, C.A. (2003). Differentiating instruction in response to student readiness, interest, and learning profile in academically diverse classrooms: a review of literature. Journal for the Education of the Gifted, 27, (2/3), 119-145.

-Van de Pol, J., Volman, M., and Beishuizen, J. (2010). Scaffolding in Teacher-Student interaction: a decade of research. Educ. Psychol. Rev. 22, 271-296. doi: 10.1007/s10648-010-9127-6

-Wise, A. F., \& O'Neill, D. K. (2009). Beyond More Versus Less: A Reframing of the Debate on Instructional Guidance. In S. Tobias \& T. M. Duffy (Eds.), Constructivist Instruction: Success or Failure? (pp. 82-105). New York: Routledge.

-Zmuda, A., Ullman, D., \& Curtis, G. (2015). Learning personalized. Francisco, CA:Josey-Bass. 